\title{
Accuracy of Dongjui analyzer for reducing the number of unnecessary urine cultures in an outpatient setting
}

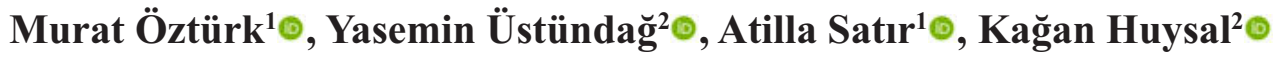 \\ ${ }^{1}$ Department of Urology, University of Health Sciences, Bursa Yüksek Ihtisas Training and Research Hospital, Bursa, Turkey \\ ${ }^{2}$ Department of Clinical Laboratory, University of Health Sciences, Bursa Yüksek Ihtisas Training and Research Hospital, Bursa, Turkey
}

\begin{abstract}
Objectives: The purpose of this study was to evaluate the diagnostic performance of the Dongjui DJ-8602 urinary analyzer for reducing the number of unnecessary urine cultures in patients with suspected urinary tract infection (UTI).

Methods: This study was designed as a retrospective study performed in patients with suspected UTI from August 1, 2018 to December 1, 2018. Clinical data, C reactive protein, blood hematologic counts were evaluated. Using positive culture results as the gold standard, the cut-off values by the receiver operating characteristic curve technique, sensitivity, and specificity were calculated.

Results: The median values of urine leukocyte levels were 31 cells/high power field (HPF) in the culturepositive group and 5 leukocytes/HPF in the culture-negative group, respectively. The area under the curve for leukocyte and bacteria count were $0.753(95 \% \mathrm{Cl}, 0.642$ to 0.862$)$ and $0.581(95 \% \mathrm{Cl}, 0.438$ to 0.725$)$, respectively. A leukocyte count $\geq 2$ cells/HPF, resulting the best sensitivity of $96.3 \%(95 \% \mathrm{Cl}: 81.03 \%$ to $99.48 \%)$ and a negative predictive value (NPV) of $96.4 \%(95 \% \mathrm{Cl}: 79.35 \%$ to $99.48 \%)$.

Conclusions: The use of the Dongjui DJ-8602 urinary sediment and chemistry analyzer did not accurately predict the outcome of urine cultures with an unsatisfactory sensitivity and NPVs of bacteria counts.

Keywords: Urinalysis, urinary tract infection, urine culture, instrumentation, bacteriuria
\end{abstract}

$\mathrm{U}$ rinary tract infection (UTI) is defined as the presence of microbial pathogens that involve any part of the urinary tract without known functional or anatomical abnormalities of the urinary tract. UTIs are among the most common infections reported in outpatient services [1].

The gold standard for the diagnosis of UTI is midstream urine culture, but it is a laborious and expensive process. Rejection of negative samples with the urinalysis test results has drawn attention to provide reduction in the number of unnecessary cultures [2]. However, there is a variable performance reported in the literature; in some of the studies the absence of cells or bacteria was found to be a useful screen to prevent urine culture, while there are still some concerns in other studies [2-6].

Many manufacturers have developed fully automated, integrated urine analyzers [7]. Automated urinalyzers as a screening system to rule out UTI are evaluated by their diagnostic sensitivity, specificity, accuracy, and area under receiver-operating-characteristic (ROC) curve [8]. Some authors suggest that certain analyzers are controversial to screen urine for UTI $[2,5]$. Due to differences in their performance, each

How to cite this article: Öztürk M, Üstündağ Y, Satır A, Huysal K. Accuracy of Dongjui analyzer for reducing the number of unnecessary urine cultures in an outpatient setting. Eur Res J 2022;(3):389-395. DOI: 10.18621/eurj.855509

Address for correspondence: Murat Öztürk, MD., Associate Professor, University of Health Sciences, Bursa Yüksek Ihtisas Training and Research Hospital, Department of Urology, Mimar Sinan Mah., Emniyet Cad., Yıldırım,Bursa,Turkey.E-mail: muratozturkdr@hotmail.com 
one needs to be evaluated separately. It is important to know how confident is each prediction outcome, otherwise false positive or false negative results can create diagnostic uncertainty. Manufacturer claims need to be verified independently, with the introduction of a new automated analyzer in a laboratory $[2,9]$.

Recently, the Dongjui DJ-8602 urinary sediment and chemistry analyzer (Xuzhou Dongjiu Electronic Technology Co., Ltd, China) a fully automatic system that includes one DJ-860 automatic urine sediment analyzer and one DJ-900 automatic urine chemistry analyzer was introduced.

The purpose of this study was to evaluate the diagnostic performance of the Dongjui DJ-8602 urinary analyzer as a means of reducing the number of urine samples requiring culture in patients with suspected UTI.

\section{METHODS}

This study was designed as a retrospective study performed in routine care adult patients with suspected UTI admitted to the urology outpatient clinic from $\mathrm{Au}-$ gust 1, 2018 to December 1, 2018. Data were retrospectively reviewed for the diagnostic performance of Dongui urinalysis system results for excluding culture negative patients. The protocol of the study was conducted in accordance with the Second Declaration of Helsinki.

Only patients with both clinical information and laboratory tests at admission were available were involved. The time for completing the laboratory data in relation to the receipt time was 2 hours after receipt. Exclusion criteria were: catheter urines, urines obtained via invasive procedures, pregnant women, children. Patients were excluded if they had been hospitalized, had been prescribed antimicrobial agents, had been seen by physicians within one month before entering the study. All of these attempts were performed to reduce the number of false-negative culture test results.

Variables recorded to patient files were taken: cloudy urine, foul-smelling urine on examination, any nocturia, dysuria, urgency, urine frequency, flue like symptoms, fever, mid-back pain, lower abdominal cramping, tiredness or fatigue, burning sensation in the bladder, symptom duration/day.
The following markers measured as part of routine care recorded were taken from the laboratory information system (LIS) data: C-reactive protein (CRP) (normal range $<3.0 \mathrm{mg} / \mathrm{dl}$ ), blood hematologic counts on the Coulter LH 750 cell analyzer (Beckman Coulter, Inc., Miami, USA). The neutrophile-lymphocyte count ratio (NLR) was calculated by dividing the absolute neutrophil count by the absolute lymphocyte count. The platelet to lymphocyte count ratio was calculated by dividing the absolute platelet count to lymphocyte count (PLR).

Urine culture results recorded to LIS data from urine samples sent to the laboratory were evaluated. A sample was considered culture-positive if it contained a pure culture of $\geq 105$ of colony forming units $/ \mathrm{mL}$ [10]. Pathogenic microorganisms were identified using the Vitek 2 automated system (BioMerieux, St. Louis, Missouri, USA).

Urinalysis test results by the DJ-8602 urinary sediment and chemistry analyzer (Xuzhou Dongjiu Electronic Technology Co., Ltd, China) recorded to LIS were evaluated. DJ-8602 urinary sediment and chemistry analyzer is a fully automatic system which includes one DJ-860 automatic urine sediment analyzer and one DJ-900 automatic urine chemistry analyzer. The automatic urine sediment analyzer system uses planar flow technology and morphological identification technology applying the support vector machine image processing method.

Microscopic internal quality control results studied with an Urit QC22 Control (level 2; lot 6318600402 and negative control lot, 20170301) during the study period. Urit Strip internal quality control results studied with an IQ-11 (lot 55180007). Our laboratory was participated in the urinalysis external quality control program (KBUDEK, İstanbul, Turkey).

\section{Statistical Analysis}

Statistical analyses were performed using SPSS 21.0 for Windows (SPSS Inc., Chicago, IL, USA), with culture results defined as the 'gold standard.' Samples were divided into two groups: culture negative and culture positive. Parameters with a normal distribution were evaluated using the KolmogorovSmirnov test. Comparison of quantitative data and intergroup comparisons of parameters were performed using Student's t-test or the Mann-Whitney U test. The chi-square test was used for the comparison of quali- 
Table1. Clinical and laboratory characteristics of patients

\begin{tabular}{|c|c|c|c|}
\hline & $\begin{array}{c}\text { UTI } \\
\text { n (\%) }\end{array}$ & $\begin{array}{c}\text { No UTI } \\
\text { n (\%) }\end{array}$ & $p$ value \\
\hline Age (years) $($ mean \pm SD) & $48 \pm 15$ & $40 \pm 12$ & 0.090 \\
\hline \multicolumn{4}{|l|}{ Gender } \\
\hline Male & $21 \%$ & $9 \%$ & \\
\hline Female & $79 \%$ & $91 \%$ & \\
\hline BMI $\left(\mathrm{kg} / \mathrm{m}^{2}\right)($ mean $\pm \mathrm{SD})$ & $24.8 \pm 3.3$ & $25.4 \pm 4.8$ & 0.594 \\
\hline Diabetes mellitus & $20 \%$ & $4.5 \%$ & $<0.001$ \\
\hline \multicolumn{4}{|l|}{ Clinical predictors of diagnosis } \\
\hline Foul smelling urine & $59.2 \%$ & $45.7 \%$ & 0.216 \\
\hline Cloudy urine & $44.4 \%$ & $45.7 \%$ & 0.905 \\
\hline Dysuria & $95.6 \%$ & $96.8 \%$ & 0.326 \\
\hline Nocturia & $42.9 \%$ & $44.6 \%$ & 0.225 \\
\hline Urgency & $81 \%$ & $47 \%$ & 0.006 \\
\hline Urinary frequency & $93 \%$ & $98 \%$ & 0.101 \\
\hline Flue like symptoms & $14.8 \%$ & $18.0 \%$ & 0.692 \\
\hline Fever & $7.4 \%$ & $7.4 \%$ & 0.995 \\
\hline Mid-back pain & $40.7 \%$ & $42.5 \%$ & 0.867 \\
\hline Burning sensation & $77.7 \%$ & $78.7 \%$ & 0.916 \\
\hline Lower abdominal cramping & $22.2 \%$ & $35.1 \%$ & 0.207 \\
\hline Tiredness or fatique & $37.0 \%$ & $29.7 \%$ & 0.303 \\
\hline Suprapubic warm sensation & $59.2 \%$ & $61 . \%$ & 0.196 \\
\hline Symptom duration/day (median [IQR]) & $4(4)$ & $4(4)$ & 0.778 \\
\hline \multicolumn{4}{|l|}{ Laboratory data } \\
\hline $\mathrm{CRP}(\mathrm{mg} / \mathrm{dl})$ & $4.7(26)$ & $3.0(1.6)$ & 0.030 \\
\hline \multicolumn{4}{|l|}{ Haemogram test } \\
\hline $\mathrm{WBC}\left(\times 10^{9} / \mathrm{L}\right)$ & $8.4(4.1)$ & $7.1(3.1)$ & 0.020 \\
\hline Neutrophil $\left(\times 10^{9} / \mathrm{L}\right)$ & $5.4(3.6)$ & $4.2(1.7)$ & 0.090 \\
\hline Lymphocyte $\left(\times 10^{9} / \mathrm{L}\right)$ & $2.2(0.7)$ & $2.3(0.8)$ & 0.228 \\
\hline NLR & $2.3(1.8)$ & $1.7(0.9)$ & 0.023 \\
\hline Platelet & $266(66)$ & $276(77)$ & 0.953 \\
\hline PLR & $132(69)$ & $121(43)$ & 0.144 \\
\hline MPV (fL) & $8.1(1.0)$ & $8.6(1.4)$ & 0.067 \\
\hline RDW (\%) & $139(2.8)$ & $136(1.7)$ & 0.330 \\
\hline \multicolumn{4}{|l|}{ Urine } \\
\hline \multicolumn{4}{|l|}{ Dipstick } \\
\hline $\mathrm{LE} \geq 1+$ & $81.4 \%$ & $45.7 \%$ & 0.004 \\
\hline $\mathrm{NO}_{2}$ & $33.3 \%$ & $4.2 \%$ & $<0.001$ \\
\hline \multicolumn{4}{|l|}{ Microscopy } \\
\hline Leukocyte (count/HPF) & $31(130)$ & $5(14)$ & $<0.001$ \\
\hline Erythrocyte & $8(36)$ & $4(12)$ & 0.019 \\
\hline Bacteria(count/HPF) & $0(43)$ & $0(6)$ & 0.198 \\
\hline
\end{tabular}

$\mathrm{BMI}=$ body mass index, $\mathrm{CRP}=\mathrm{C}$-reactive protein, $\mathrm{WBC}=$ white blood cell, $\mathrm{NLR}=$ neutrophil to lymphocyte ratio, $\mathrm{PLR}=$ platelet to lymphocyte ratio, MPV = mean platelet volume, RDW = red cell distribution width, HPF = high power field, IQR = interquartile range; $\mathrm{SD}=$ standard deviation. Chi-square test for Association 
tative data. ROC curves were created to identify the cut-off points for variables.

Using positive culture results as the gold standard, sensitivity, specificity, positive predictive value (PPV; the post-test probability of an outcome for positive tests), negative predictive value (NPV; the post-test probability of an outcome for negative tests ), accuracy (the proportion of true results in the population), positive likelihood ratio (LR+) (the probability of a person who has the disease testing positive divided by the probability of a person who does not have the disease testing positive), negative likelihood ratio (LR-) (the probability of a person who has the disease testing negative divided by the probability of a person who does not have the disease testing negative), diagnostic odds ratio $\mathrm{LR}+/ \mathrm{LR}$ - and accuracy (true positives + true negatives)/ all cases were calculated.

\section{RESULTS}

In total, 121 patients were found to be eligible for study enrollment. Table 1 shows characteristics of patients on admission. The study group ranged in age from 18 to 74 years. Significant bacterial growth was detected in 27 (20.18\%) specimens. Escherichia coli grew in $23(95 \%)$ of the positive cultures. The CRP ( $p$ $=0.030)$, WBC $(p=0.020)$ and NLR $(p=0.023)$ levels were higher in patients with UTI.

The median values of urine leukocyte levels were 31 cells/HPF and 8 cells/high power field (HPF) for erytrocytes with the DJ-8602 urinary sediment and chemistry analyzer in the culture-positive group and 5 leukocytes/HPF and 4 erytrocytes/HPF in the culture-negative group, respectively (see Table1).

ROC curves for leukocyte and bacterial counts of the urine sediment analyses are presented in Fig. 1. The AUC for leukocyte counts was $0.753(95 \% \mathrm{Cl}$, 0.642 to 0.862$)$, compared with $0.581(95 \% \mathrm{Cl}, 0.438$ to 0.725 ) for bacteria; showing acceptable discrimination power for UTI only for urine leukocyte count with a Dongjui DJ-8602 urinary sediment and chemistry analyzer (Table 2) [8].

When cut-off points for microscopy results were analysed, a leukocyte count $\geq 2$ cells/HPF, resulting in a sensitivity of $96.3 \%(95 \% \mathrm{Cl}: 81.03$ to 99.48$)$ and a NPV of 96.4 (95\% Cl: 79.35 to 99.48) (Table 3). An optimum cut-off a leukocyte count $\geq 7$ cells/HPF yielded a sensitivity of $70.3 \%$ (95\% CI: $49.82 \%$ $86.25 \%)$ and a specificity of $58.51 \%(95 \% \mathrm{CI}$ : 47.88\%-68.59\%). Bacterial counts were not different between UTI and nonUTI groups ( $p=0.198)$ (Fig. 2).

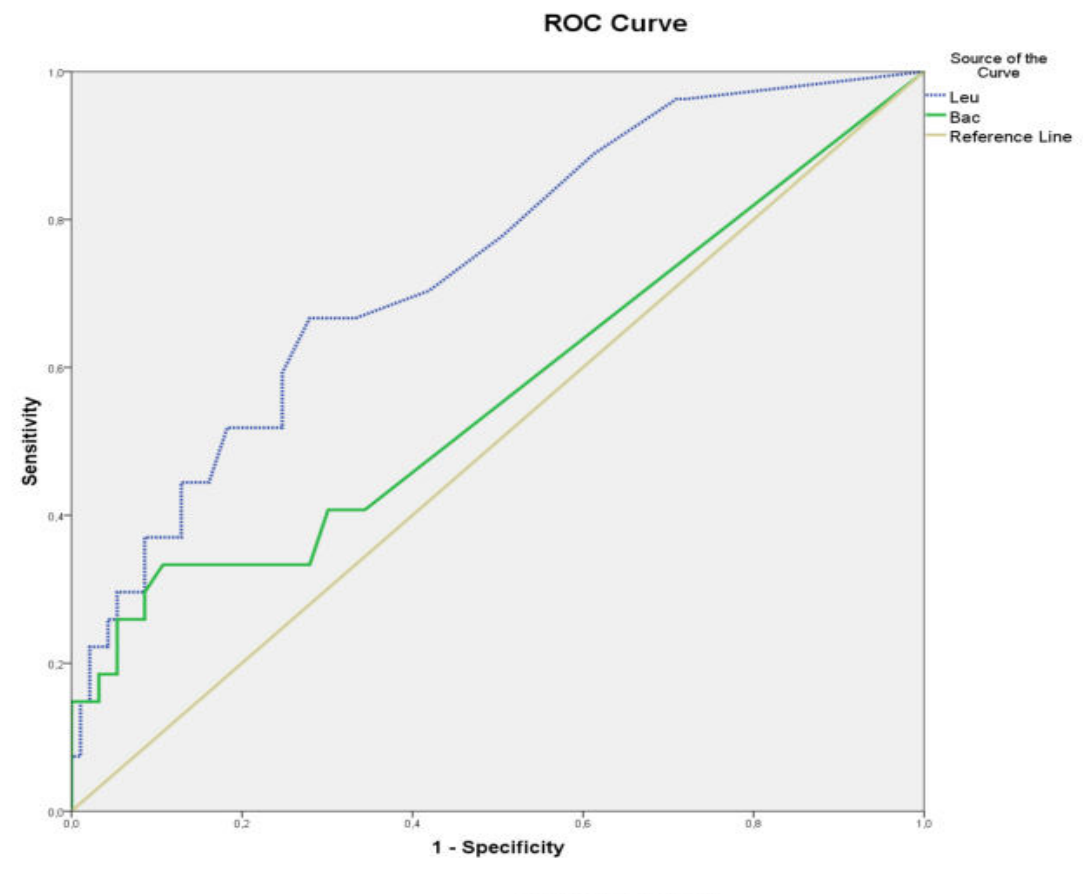

Fig. 1. Receiver operating characteristics (ROC) curve for the whole group to determine the negative culture with urinalysis test results. The optimum cut-off point for $\mathrm{WBC}$ was 4 cells/HPF. 
Table 2. Diagnostic performances of urinalysis test results for distinguishing culture positive patients from urinalysis

\begin{tabular}{lcccc}
\hline Variables & AUC & SE & Significance & 95\% CI \\
\hline Leukocyte & 0.753 & 0.057 & $<\mathbf{0 . 0 0 1 *}$ & $0.642-0.864$ \\
Erythrocyte & 0.647 & 0.059 & $\mathbf{0 . 0 2 0}$ & $0531-0.763$ \\
Bacteria & 0.581 & 0.073 & 0.221 & $0.438-0.725$ \\
Cylendir & 0.542 & 0.069 & 0.532 & $0.406-0.677$ \\
Crystal & 0.518 & 0.068 & 0.789 & $0.385-0.650$ \\
\hline
\end{tabular}

$\mathrm{AUC}=$ area under curve, $\mathrm{SE}=$ standard error, $\mathrm{CI}=$ confidence interval. ${ }^{*}$ Null hypothesis $=$ true area $=0.5$

Table 3. The discriminative and predicting power of the each individual urinalysis variable

\begin{tabular}{|c|c|c|c|c|c|c|c|}
\hline Parameter & $\begin{array}{c}\text { SE (\%) } \\
(95 \% \text { CI) }\end{array}$ & $\begin{array}{c}\text { SP (\%) } \\
(95 \% \text { CI) }\end{array}$ & $\begin{array}{l}\text { PPV (\%)* } \\
(95 \% \text { CI) }\end{array}$ & $\begin{array}{l}\text { NPV (\%)* } \\
(95 \% \text { CI) }\end{array}$ & $\begin{array}{c}\text { LR+ } \\
(95 \% \text { CI) }\end{array}$ & $\begin{array}{c}\text { LR- } \\
(95 \% \text { CI) }\end{array}$ & $\begin{array}{c}\text { Accuracy (\%)* } \\
(95 \% \text { CI) }\end{array}$ \\
\hline \multicolumn{8}{|l|}{ Dipstick } \\
\hline $\mathrm{LE} \geq 1+$ & $\begin{array}{c}81.48 \\
(61.92-93.70)\end{array}$ & $\begin{array}{c}54.26 \\
(43.66-64.58)\end{array}$ & $\begin{array}{c}33.85 \\
(27.80-40.47)\end{array}$ & $\begin{array}{c}91.07 \\
(81.90-95.83)\end{array}$ & $\begin{array}{c}1.78 \\
(1.34-2.37)\end{array}$ & $\begin{array}{c}0.34 \\
(0.15-0.77)\end{array}$ & $\begin{array}{c}60.33 \\
(51.04-69.11)\end{array}$ \\
\hline $\mathrm{NO} 2 \geq 1+$ & $\begin{array}{c}66.67 \\
(46.04-83.48)\end{array}$ & $\begin{array}{c}95.74 \\
(89.46-98.83)\end{array}$ & $\begin{array}{c}81.82 \\
(62.45-92.41)\end{array}$ & $\begin{array}{c}90.91 \\
(85.41-94.47)\end{array}$ & $\begin{array}{c}15.67 \\
(5.79-42.39)\end{array}$ & $\begin{array}{c}0.35 \\
(0.20-0.59)\end{array}$ & $\begin{array}{c}89.26 \\
(82.33-94.15)\end{array}$ \\
\hline \multicolumn{8}{|l|}{ Microscopy } \\
\hline $\mathrm{WBC}^{1}(\geq 2)$ & $\begin{array}{c}96.3 \\
(81.03-99.91)\end{array}$ & & $\begin{array}{c}27.96 \\
(25.07-31.04)\end{array}$ & $\begin{array}{c}96.43 \\
(79.35-99.48)\end{array}$ & $\begin{array}{c}1.35 \\
(1.17-1.57)\end{array}$ & $\begin{array}{c}0.13 \\
(0.02-0.91)\end{array}$ & $\begin{array}{c}43.80 \\
(34.80-53.11)\end{array}$ \\
\hline $\mathrm{WBC}^{2}(\geq 7)$ & $\begin{array}{c}70.37 \\
(49.82-86.25)\end{array}$ & $\begin{array}{c}58.51 \\
(47.88-68.59)\end{array}$ & $\begin{array}{c}32.76 \\
(25.69-40.70)\end{array}$ & $\begin{array}{c}87.30 \\
\text { (78.95 to } 92.65)\end{array}$ & $\begin{array}{c}1.70 \\
(1.20-2.39)\end{array}$ & $\begin{array}{c}0.51 \\
(0.28-0.93)\end{array}$ & $\begin{array}{c}61.16 \\
(51.87-69.88)\end{array}$ \\
\hline Bacteria $^{1}(\geq 3)$ & $\begin{array}{c}40.74 \\
(22.39-61.20)\end{array}$ & $\begin{array}{c}70.21 \\
(59.90-79.21)\end{array}$ & $\begin{array}{c}28.21 \\
(18.47-40.53)\end{array}$ & $\begin{array}{c}80.49 \\
(74.61-85.28)\end{array}$ & $\begin{array}{c}1.37 \\
(0.79-2.37)\end{array}$ & $\begin{array}{c}0.84 \\
(0.60-1.18)\end{array}$ & $\begin{array}{c}63.64 \\
(54.40-72.19)\end{array}$ \\
\hline Bakteri $^{2}(\geq 18)$ & $\begin{array}{c}33.33 \\
(16.52-53.96)\end{array}$ & $\begin{array}{c}86.17 \\
(77.51-92.43)\end{array}$ & $\begin{array}{c}40.91 \\
(24.94-59.06)\end{array}$ & $\begin{array}{c}81.82 \\
(77.30-85.60)\end{array}$ & $\begin{array}{c}2.41 \\
(1.16-5.02)\end{array}$ & $\begin{array}{c}0.77 \\
(0.59-1.02)\end{array}$ & $\begin{array}{c}74.38 \\
(65.65-81.88)\end{array}$ \\
\hline
\end{tabular}

$\mathrm{LE}=$ leukocyte esterase, $\mathrm{NO}_{2}=$ nitrite, $\mathrm{SE}=$ sensitivity, $\mathrm{SP}=$ specificity, $\mathrm{NPV}=$ negative predictive value, $\mathrm{PPV}=$ positive predictive value, $\mathrm{LR}+=$ positive likelihood ratio, $\mathrm{LR}-=$ negative likelihood ratio, Accuracy $=$ correctly classified $\%$. *These values are dependent on disease prevalence. ${ }^{1}$ Highest sensitivity, ${ }^{2} \mathrm{Cut}-$ off

\section{DISCUSSION}

Like others before us, we found that negative urine cultures constitute a large percentage of the clinical laboratory workload in our hospital $[2,3,5,11]$. Only the ROC analysis of the urinary leukocyte counts of the Dongjui DJ-8602 urine sediment analyzer shows an acceptable AUC value of 0.753 . However, this value is not outstanding and when used alone may lead to diagnostic uncertainty [13].

In our study, the sensitivity, specificity, and AUC of leukocyte count were higher than those of bacteria count; similar to Kocer et al.'s [12] findings. A screening analyzer to reduce the number of negative urine culture samples is reliable only when a high sensitivity and high negative predictive values are obtained. And ideally, the sensitivity should be $>90-95 \%$ to rule out disease $[14,15]$. The cut-off point should be low enough to exclude the minimum urine samples.

A detailed analysis showed that the $\mathrm{WBC} \geq 2$ cells / HPF gave only one false negative result, with a sensitivity of $96.3 \%$ and a NPV of $96.4 \%$. This cut-off point will reduce the number of samples sent to the laboratory for culture. However, the harmful effects of false negative findings should be taken into account. On the other hand, predicting negative results may prevent the risk of unnecessary initiation of antibiotic treatment.

Our results were comparable to previous studies with automated microscopy methods such as digital imaging with laminar flow (İQ 200) and verified digital images (sediMAX, FUS-100, Cobas u 700, Atel- 


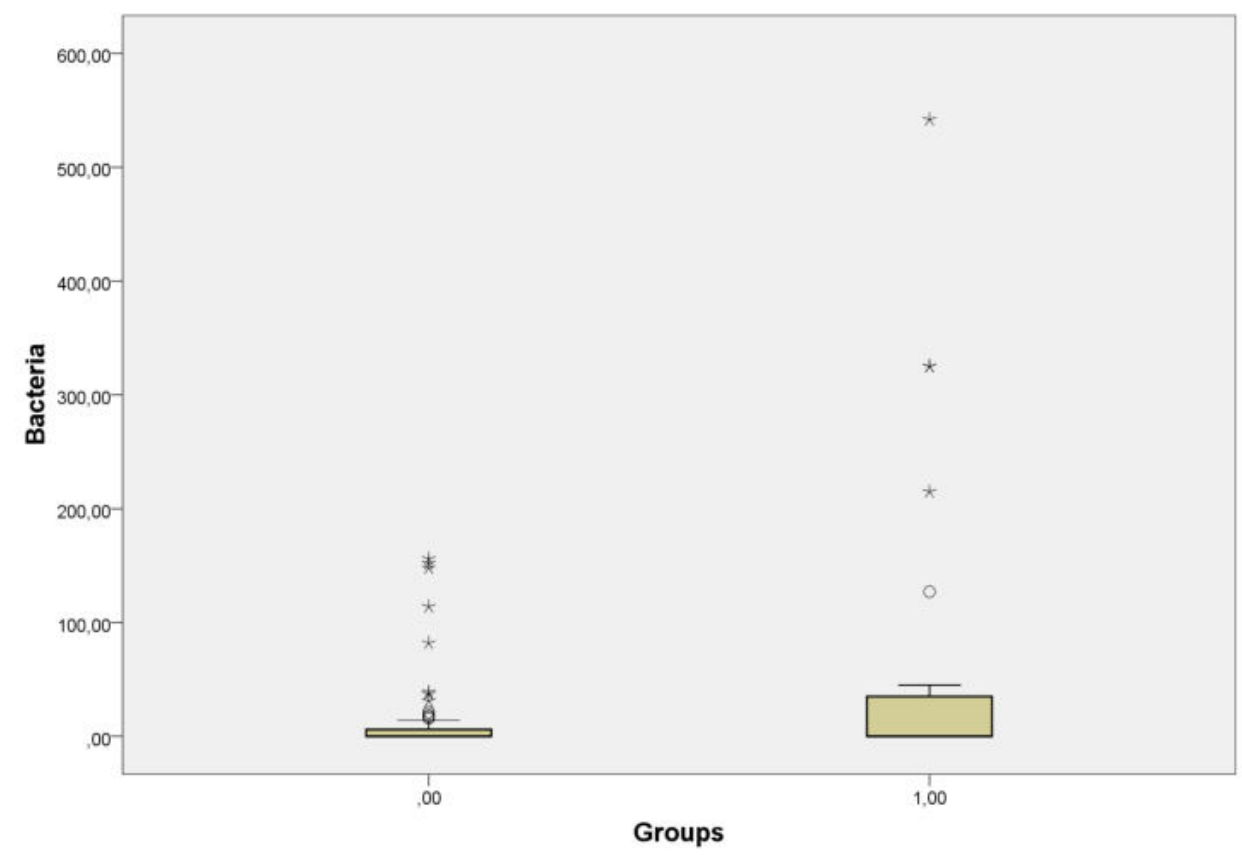

Fig. 2. Comparison of quantitative bacterial counts between groups. Bacteria: count/HPF; Group 0: Patients without UTI, Group 1: Patients with UTI. Box represents the confidence interval (95\%).

lica 1500) that leukocyte parameter is better than those of bacteria count [16] . However differences based on the definition of negative urine, variation in cut off levels applied, patient populations and clinical situations makes it difficult to directly compare study results [16].

In our study, we found that the bacteriuria parameter of the Dongjui DJ-8602 urine sediment analyzer, which uses an image analysis method has poor discriminatory power for UTI. Our results are consistent with other studies that the bacteriuria parameter with automated microscopy cannot be used alone to reduce the number of negative urine culture samples [17-20].

The sensitivity of the urine dipstick test for nitrites was low $(66.7 \%)$ with higher levels of specificity $(95.74 \%)$ comparable to those of the other studies [2, $21,22]$. The sensitivity of LE was acceptable (81.48\%.) [15]. Results produced by dipstick should not be overly relied upon for screening [23, 24].

\section{Limitations}

The main limitations of this study include the use of retrospective data, inclusion of data from only one urology department. A single cut off value of 105 colony-forming unit $(\mathrm{CFU}) / \mathrm{ml}$ was used for the cul- ture. Also, the delay from initiation until publication is a weakness.

\section{CONCLUSION}

In conclusion, we found that the use of the Dongjui DJ-8602 urinary sediment and chemistry analyzer did not accurately predict the outcome of urine cultures with low sensitivity and NPVs of bacteria counts.

\section{Authors' Contribution}

Study Conception: MÖ, YÜ, KH; Study Design: YÜ, KH; Supervision: MÖ, YÜ, AS, KH; Funding: MÖ, YÜ, AS, KH; Materials: MÖ, YÜ, AS, KH; Data Collection and/or Processing: MÖ, YÜ, AS, KH; Statistical Analysis and/or Data Interpretation: MÖ, YÜ, AS, KH; Literature Review: MÖ, YÜ, AS, KH; Manuscript Preparation: MÖ, YÜ, AS, KH and Critical Review: MÖ, YÜ, AS, KH.

\section{Conflict of interest}

The authors disclosed no conflict of interest during the preparation or publication of this manuscript. 


\section{Financing}

The authors disclosed that they did not receive any grant during conduction or writing of this study.

\section{REFERENCES}

1. Grigoryan L, Trautner BW, Gupta K. Diagnosis and management of urinary tract infections in the outpatient setting: a review. JAMA 2014;312:1677-84.

2. Huysal K, Budak YU, Karaca AU, Aydos M, Kahvecioğlu S, Bulut M, et al. Diagnostic accuracy of uriSed automated urine microscopic sediment analyzer and dipstick parameters in predicting urine culture test results. Biochem Med (Zagreb) 2013;23:211-7.

3. Falbo R, Sala MR, Signorelli S, Venturi N, Signorini S, Brambilla P. Bacteriuria screening by automated whole-field-imagebased microscopy reduces the number of necessary urine cultures. J Clin Microbiol 2012;50:1427-9.

4. Ma J, Wang C, Yue J, Li M, Zhang H, Ma X, et al. Clinical laboratory urine analysis: comparison of the UriSed automated microscopic analyzer and the manual microscopy. Clin Lab 2013;59:1297-1303.

5. Bignardi GE. Validation and verification of automated urine particle analysers. J Clin Pathol 2017;70:94-101.

6. Shang YJ, Wang QQ, Zhang JR, Xu YL, Zhang WW, Chen Y, et al. Systematic review and meta-analysis of flow cytometry in urinary tract infection screening. Clin Chim Acta 2013;424:905.

7. Budak YU, Huysal K. Comparison of three automated systems for urine chemistry and sediment analysis in routine laboratory practice. Clin Lab 2011;57:47-52.

8. Pereiara P. Evaluation of rapid diagnostic test performance. In: Proof and Concepts in Rapid Diagnostic Tests and Technologies. Saxena SK (ed.), 1st ed. Inteck, Croatia; 2016:p.147.

9. Zaman Z, Roggeman S, Verhaegen J. Unsatisfactory performance of flow cytometer F-100 and urine strips in predicting outcome of urine cultures. J Clin Microbiol 2001;39:4169-71.

10. Graham JC, Galloway A. ACP Best Practice No 167: the laboratory diagnosis of urinary tract infection. J Clin Pathol 2001;54:911-9.

11. Brilha S, Proença H, Cristino JM, Hänscheid T. Use of a flow cytometry (Sysmex) UF-100) to screen for positive urine cultures: in search for the ideal cut-off. Clin Chem Lab Med 2010;48:289-92.

12. Kocer D, Sariguzel FM, Ciraci MZ, Karakukcu C, Oz L. Di- agnostic accuracy of a new urinalysis system, DongJiu, for diagnosis of urinary tract infection. Ann Clin Lab Sci 2015;45:68691.

13. McHugh LC, Snyder K, Yager TD. The effect of uncertainty in patient classification on diagnostic performance estimations. PLoS One 2019;14:e0217146.

14. Akobeng AK. Understanding diagnostic tests 1: sensitivity, specificity and predictive values. Acta Paediatr 2007;96:338-41. 15. European Confederation of Laboratory Medicine. European urinalysis guidelines. 2000;231:1-86.

16. Oyaert M, Delanghe J. Progress in automated urinalysis. Ann Lab Med 2019;39:15-22.

17. Stürenburg E, Kramer J, Schön G, Cachovan G, Sobottka I. Detection of significant bacteriuria by use of the iQ200 automated urine microscope. J Clin Microbiol 2014;52:2855-60.

18. Sterry-Blunt RE, S Randall K, J Doughton M, H Aliyu S, A Enoch D. Screening urine samples for the absence of urinary tract infection using the sediMAX automated microscopy analyser. J Med Microbiol 2015;64:605-9.

19. Kocer D, Sarıguzel FM, Karakukcu C. Cutoff values for bacteria and leukocytes for urine sediment analyzer FUS200 in culture-positive urinary-tract infections. Scand J Clin Lab Invest 2014;74:414-7.

20. Zaman Z, Fogazzi GB, Garigali G, Croci MD, Bayer G, Kranicz T. Urine sediment analysis: analytical and diagnostic performance of sediMAX - a new automated microscopy imagebased urine sediment analyser. Clin Chim Acta 2010;411:147-54. 21. Ducharme J, Neilson S, Ginn JL. Can urine cultures and reagent test strips be used to diagnose urinary tract infection in elderly emergency department patients without focal urinary symptoms? 2007;9:87-92.

22. Marques AG, Doi AM, Pasternak J, Damascena MDS, França $\mathrm{CN}$, Martino MDV. Performance of the dipstick screening test as a predictor of negative urine culture. Einstein (Sao Paulo) 2017;15:34-9.

23. Dadzie I, Quansah E, Dakorah MP, Abiade V Takyi-Amuah E, Adusei R. The effectiveness of dipstick for the detection of urinary tract infection. Can J Infect Dis Med Microbiol 2019;2019:8642628.

24. Krongvorakul J, Phundhusuwannakul S, Santanirand P, Kunakorn M. A flow cytometric urine analyzer for bacteria and white blood cell counts plus urine dispstick test for rapid screening of bacterial urinary tract infection. Asian Biomed 2012;6:6018 . 